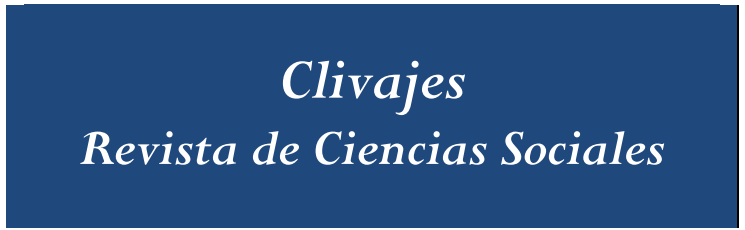

Clivajes. Revista de Ciencias Sociales ISSN: 2395-9495

https://goo.gl/uEV8kk

IIH-S, UV, México

Erick Alfonso Galán Castro

LA ANTROPOLOGÍA RELACIONAL: UNA POSIBILIDAD EPISTEMOLÓGICA

Clivajes. Revista de Ciencias Sociales. Año V, número 9, enero-junio 2018, pp.1-26.

Instituto de Investigaciones Histórico-Sociales

Universidad Veracruzana. México

Recibido: 01-10-2017

Aceptado: 30-10-2017

Dictaminado: 11-11-2017

Publicado: 01-01-2018 


\title{
LA ANTROPOLOGÍA RELACIONAL: UNA POSIBILIDAD EPISTEMOLÓGICA
}

\author{
Erick Alfonso Galán Castro*
}

\section{Resumen}

El objetivo del artículo es exponer y poner a debate el giro relacional de las ciencias sociales como alternativa teórico-metodológica para entender la realidad actual, donde las barreras físico-geográficas y los grupos sociales no tocados por la civilización moderna son, en lo general, inexistentes. La perspectiva relacional antropológica propone que el objeto de estudios empíricos y reflexiones teóricas se sitúe en torno a relaciones sociales, definidas como referencias simbólicas, organizativas y pragmáticas, desde las cuales los actores sociales pueden generar o actualizar sus vínculos.

Palabras clave: Antropología, Realismo Crítico, Enfoque Relacional

\section{INTRODUCCIÓN}

La antropología ha desarrollado aportes teórico-metodológicos en torno a una visión sustancialista de su objeto de estudio; por un lado, han surgido propuestas teóricas en las que el objeto de estudio de la antropología son las normas, las tradiciones y las costumbres, en tanto constitutivas de un grupo social determinado, 1) sujetas a comparación con respecto a las de otros grupos sociales o 2) descritas de manera que la forma de exposición literaria tiene mayor importancia que la comprensión y explicación de lo social -a esto llamo "sustancialismo costumbrista"-; por otro lado, se ha considerado objeto de estudio de esta disciplina a las características y mecanismos desde los cuales funciona y tiende hacia la autorregulación, entendiendo la producción humana como un esfuerzo de la sociedad para lograr una mayor integración "sustancialismo holista".

El problema con ambas perspectivas de análisis antropológico ha sido la llegada de un momento histórico al que Pierpaolo Donati (2006) denomina "dopomodernidad”. 1

\footnotetext{
* Doctor en Investigación en Ciencias Sociales por FLACSO México, maestro en Antropología Social por CIESAS-Golfo, licenciado en Antropología Social por la UV, ha hecho estudios acerca de minorías religiosas y participación ciudadana, y sobre identidad y acción colectiva en movimientos sociales de víctimas.

${ }^{1}$ En otros textos del autor (2007; 2011), se le denomina after modernity; en este caso, retomo la traducción de Pablo García Ruíz, procedente del italiano "doppomodernitá", que destaca el término y remite a un fenómeno diferente al de “posmodernidad”.
} 
De acuerdo con el autor, ésta constituye una fase histórica en que "la identidad se define a través y con la relación, pero no ya con la negación dialéctica, sino mediante un establecimiento de una relación con lo otro” (p. 68). Así, se instituye una diferencia en la forma como se ha definido la vida social en éste, con respecto a otros dos momentos históricos. Durante un periodo clásico - de la antigüedad a la ilustración-, la identidad de y la referencia al hombre se daba en función de una coincidencia consigo mismo, es decir, había una tendencia mayor hacia la integración, que hacia la segmentación de la sociedad; la división del trabajo se definía desde lo sexual, y el sentido religioso y la pertenencia a un espacio establecían la diferencia entre un grupo social y otro. Con el advenimiento de la modernidad - de la ilustración a la era de la interconectividad en tiempo real-, la identidad se define en función de la negación de lo otro; surgen el Estado moderno y se registra el auge del capitalismo, así como de las narrativas nacionalistas y del progreso basado en el diálogo crítico. La dopomodernidad es continuación de la modernidad en algunos aspectos, como la presencia del Estado, de las relaciones económicas basadas en el capitalismo, en la persistencia de la desigualdad y la exclusión, pero, en ésta, el vínculo social se desplaza fuera del espacio físico, de las barreras existentes, a partir de las fronteras nacionales.

Actualmente, es posible obtener trabajo en México para empresas con matriz en Estados Unidos, comunicarse en tiempo real con personas que viven en Japón, Francia o la Isla de Tristán de Acuña en el Atlántico Sur. Los eventos que transforman nuestra cotidianidad no ocurren necesariamente en nuestra inmediatez, como las negociaciones entre Estados Unidos y Cuba mediadas por el papa Francisco, o los atentados yihadistas perpetrados por el Estado Islámico en París. La dopomodernidad, entonces, plantea un problema teórico-metodológico muy fuerte para la antropología: si ya no hay grupos sociales puros, es decir, no trastocados por eventos globales, y las transformaciones de la realidad no suceden en el espacio físico inmediato, sino deslocalizadamente y de manera más veloz que antes, ¿qué es lo que mantiene unida a la sociedad?, ¿cómo conocer y conceptualizar la experiencia humana frente a un escenario como éste?

En este trabajo proponemos un giro epistemológico hacia la antropología, destacando la importancia de los vínculos para comprender lo humano en un momento histórico sui generis. No debe confundirse la dopomodernidad con la posmodernidad. Desde la perspectiva de Donati (2006), esta última supone una exageración de la modernidad (p. 66); excesos tales como la radicalización de los nacionalismos, la eliminación de la otredad, el desarrollo científico - que generó mayor contaminacióno la fabricación de armas letales, condujeron a algunos teóricos y filósofos a optar por 
un "camino contrario" a la modernidad; esto es, a rechazar las grandes narrativas, la ciencia racional, los nacionalismos, etc. A tales pensadores se les llamó "posmodernos" (Lyotard, 1987). La dopomodernidad no es en sí misma una propuesta teórica, sino un momento histórico en que los hechos han generado una forma distinta de vincularse socialmente, y tanto el espacio como las fronteras pierden relevancia para conformar a la sociedad.

En primer lugar, se hace un análisis crítico de las teorías antropológicas clásicas, a la luz de la dopomodernidad y de los alcances heurísticos de dichas corrientes, para luego explicar en qué consiste la antropología relacional y cuáles son las dimensiones teórico-metodológicas que supone un giro hacia la relación como objeto de estudio, y proponer, finalmente, algunas conclusiones.

\section{EL SUSTANCIALISMO EN LA ANTROPOLOGÍA: COSTUMBRISMO VS. HOLISMO}

El enfoque costumbrista de la antropología ha tenido una gran impronta en el modo en que los profesionales presentan el resultado de sus investigaciones, incluso entre muchos de los supuestos epistemológicos que siguen a esa presentación. De acuerdo con esta forma de sustancialismo antropológico, el trabajo del investigador, si bien al principio se asume primordialmente como el de un analista de lo exótico, se convierte en el de un creador de ficciones etnográficas, donde lo importante es generar un falso diálogo con el nativo y la voz del antropólogo se pierde para privilegiar la del sujeto investigado.

Franz Boas fue un gran crítico de los excesos de la modernidad. Su propuesta de estudio de la cultura era, más que nada, una respuesta enérgica a problemáticas como el nacionalismo extremo, el occidentalismo y los planteamientos filosófico-sociales que sustentaban una idea evolucionista sin aparentes bases científicas. El dato histórico sobre los pueblos, entonces, tenía una importancia mayor sobre las inferencias que podían desarrollarse sobre dicha información. Algunos autores, según cuya filosofía social los pueblos no occidentales eran inferiores a los propiamente occidentales - por la difusión y persistencia de sus costumbres y tradiciones, su actitud emocional, sus atributos fisiológicos o la pigmentación de su cuerpo o su capacidad craneal-, no afirmaron nada a partir de hechos científicos resultado de análisis inductivos, sino más bien de inferencias que el propio Boas calificaba de prejuicios emocionales, de inferencias asociadas al clasismo, a una visión nacionalista y racista (Boas, 1964: 34). El objeto de estudio de los antropólogos debía fincarse dentro de la crítica, con métodos de 
obtención de datos rigurosamente sistemáticos, que permitieran poner en tela de juicio dichas inferencias, ajenas a la labor científica.

Boas, de esta manera, intentó ratificar la labor racional moderna de la antropología, sobre la base de una epistemología fundada en el conocimiento de los hechos específicos para, posteriormente -y en un notable segundo término--, generar inferencias de conexión entre hechos. Esta visión ha sido la fuente epistemológica de diversos aspectos con los que la antropología actual ha perdido el carácter social de su objeto de estudio: 1) la exhaustiva labor de "salvamento cultural” implicada en la visión boasiana del trabajo antropológico cosifica la construcción social de sentido y le otorga la categoría de "reliquia en peligro" frente al arribo de la modernidad; y 2) el objeto de estudio antropológico se sitúa, indefectiblemente, en un espacio físico y geográfico, por lo que la producción humana es inequiparable - e inexplicable- fuera del lugar donde se elabora. Este último punto será abordado con mayor detalle en reflexiones de autores como Alfred Kroeber (1939), Margaret Mead (1993) y Ruth Benedict (1961, 2006).

Si la epistemología boasiana buscaba dar cuenta de lo cultural a partir de las características de la producción de tradiciones y costumbres de un pueblo, los antropólogos posmodernos llevaron esta intención a un relativismo aún más extremo. El objetivo de la antropología posmoderna se asociaba con la crítica a la modernidad, fundada en el carácter científico de la disciplina. En ese sentido, la labor de la antropología posmoderna debía basarse en la elaboración de una etnografía "evocativa”, una retórica del pasado, que intentaba mostrar un mensaje oculto, es decir, no directo ni manifiesto, al lector (Tyler, 1991; Rosaldo, 2000; Viveiros de Castro, 2004; Descola, 2004).

En un contexto de dopomodernidad, la dificultad más grave del enfoque costumbrista para una antropología social es pensar, como los posmodernos, que la labor del investigador es producir narrativas evocativas, sin intención alguna de reconocer al etnógrafo su capacidad de establecer conexiones entre hechos para explicar el objeto de estudio. Negar el potencial heurístico y analítico del investigador, y subordinarlo a mostrar una retórica persuasiva pueden constituir un obstáculo para el desarrollo del investigador.

El sustancialismo holista en la antropología social, tal como menciona Mustafá Emirbayer para la sociología, no plantea individuos, sino “"sociedades', 'estructuras' o 'sistemas sociales' autosuficientes como fuentes de acción exclusiva” (Emirbayer, 2009: 209). En el caso de la antropología social, los descubrimientos y las propuestas científicas de Emile Durkheim y Karl Marx marcaron un parteaguas para generar 
conocimiento sobre las sociedades premodernas. Por un lado, la discusión central de los holistas fue entender el objeto de la antropología, a partir de las formas en que las sociedades pueden autocrearse transhistóricamente; por otro, hubo autores que consideraban la voluntad individual sujeta a leyes de la economía política. En suma, dentro de la antropología social, el sustancialismo holista aportó las primeras grandes reflexiones en torno al carácter relacional de la vida humana, pues lejos de considerar que la sociedad o los grupos sociales podían definirse en función de sus tradiciones y costumbres, éstas tenían valor en tanto se asumieron como producto de relaciones entre individuos.

A raíz de las reflexiones de Emile Durkheim sobre la moral y el contractualismo, Marcel Mauss busca explorar los casos de los Kwakiutl, los habitantes de las Islas Trobriand, los Andamán y otros, para entender bajó qué formas puede mantenerse la solidaridad social. Dos conceptos de gran importancia le dan la respuesta: los "hechos sociales totales" y la "ley del don". El primero refiere un hecho colectivo, a veces voluntario en apariencia, pero de carácter coercitivo, donde se ven expresadas todo tipo de instituciones sociales: religiosas, jurídicas, morales, económicas (Mauss, 1971: 2); el segundo alude a uno de estos "hechos sociales totales", una norma de derecho moral, que obliga a los individuos a dar, recibir y devolver bienes para garantizar la alianza entre los individuos y evitar la guerra (Mauss, 1971: 6). En cuanto a la organización social, la lógica del don explicaría la existencia del “tabú del incesto" como un hecho visible en todas las sociedades humanas, gracias a que 1) reafirma la diferencia entre lo natural y lo cultural y 2) garantiza que las alianzas entre diversas familias permitan otro tipo de intercambios de diversos bienes (Lévi-Strauss, 1981: 21).

Las investigaciones de Lévi-Strauss sobre este tipo de alianzas, aunadas a su preocupación por concebir una teoría acerca de las estructuras del pensamiento, dieron como resultado uno de los esfuerzos intelectuales más relevantes por analizar la generación atemporal del sentido: el análisis del "pensamiento salvaje" (Lévi-Strauss, 2014: 60). La prueba más importante para refutar los planteamientos de que los pueblos no occidentales son inferiores a los occidentales se encuentra en la forma en que aprehenden al mundo. Esta antropología del conocimiento se basa en asumir que los seres humanos, en cualquier sociedad, en cualquier momento histórico, clasifican su entorno a partir de pares dicotómicos (hombre-mujer, sagrado-profano, día-noche, arriba-abajo, etc.). Los mitos son una muestra de que todas las sociedades y en todos los momentos de la historia hemos construido nuestra cultura a partir de tales distinciones dicotómicas; por ello, el hombre moderno no es distinto del primitivo. La 
comunicación entre los hombres ocurre mediante signos y símbolos, y los antropólogos, que buscan propiciar una "conversación del hombre con el hombre", deben basar su estudio de las relaciones sociales en dichos signos y símbolos (LeviStrauss, 1999: 16). Así, este esfuerzo no intentaba buscar en la producción humana de cada grupo social lo valioso que aquellos podían ser para toda la humanidad, sino mostrar a los pueblos como portadores de una estructura gnoseológica común.

Para los funcionalistas británicos, como Alfred R. Radcliffe-Brown, el objeto de estudio de la antropología social era conocer la estructura -serie de relaciones estables constitutivas de un todo-, las funciones -actividades colectivas y recurrentes para garantizar la estabilidad estructural-y el funcionamiento - proceso vital- de cada sociedad (Radcliffe-Brown, 1974: 204-205), mientras que para Malinowski (1986) es imposible saber cómo ocurre el proceso de autocreación social, sin construir un vínculo local participante con la sociedad para generar registros detallados de la vida de los nativos. El antropólogo debe discernir entre las opiniones de éstos y las inferencias y deducciones del investigador, quien adquiere autoridad en función de su capacidad para comprender el pensamiento indígena (p. 21). Malinowski entiende el carácter relacional de la producción humana, en tanto que los hechos registrados no son vistos sólo como objetos suceptibles de rescate, sino como producto de las relaciones entre los individuos para la satisfacción de necesidades individuales y colectivas (Malinowski, 1984: 56-57).

Sin embargo, tanto Radcliffe-Brown como Malinowsky tienen serias reservas hacia el análisis histórico al interior de los estudios antropológicos, pues consideran que los aportes teóricos derivados de una antropología funcional deben mostrar cómo vive la sociedad vive a través del tiempo, y no en un momento histórico determinado. Al respecto, Evans-Pritchard propone, como parte de la reflexión metodológicofuncionalista, que la antropología debe cambiar de modelo de producción de conocimiento. No son las ciencias biológicas las que deben inspirar al antropólogo, pues esto derivaría en una suerte de determinismo funcional, y, "en su forma extrema, el determinismo funcional conduce al relativismo absoluto, dejando sin sentido la teoría en sí y el pensamiento científico en su totalidad” (Evans-Pritchard, 1974: 12). Esto sólo significaría argumentar en torno a una afirmación -que comparto-, como crítica al modelo holista: sirve lo mismo para las ciencias antropológicas emitir siempre preguntas sin respuesta o respuestas para todas las preguntas. El objeto de estudio antropológico no puede pensarse en una relación de superioridad frente a cualquier 
otro tipo de conocimiento, pero tampoco llegar al extremo posmoderno de relativizar el producto de la investigación antropológica.

Finalmente, otra de las tendencias antropológicas que han sustancializado su objeto de estudio de manera notoria es la llamada "antropología marxista”. Los autores marxistas proponen que los sistemas económicos y políticos seguidos por algunas sociedades simples sustentan y pueden llegar a potencializar las relaciones de dominación propias del capitalismo, como las relaciones de clase, las de dominación por posesión de recursos naturales, las relaciones de alianzas matrimoniales y el dominio colonial (Meillassoux, 1989: 10-11).

La tendencia teórica de la antropología marxista sigue la visión holista según la cual habrá un cambio inexorable hacia el comunismo, al cual se muestra como el modelo de relaciones sociales más acabado y moderno que evitará las injusticias de los modos de producción anteriores. Por ello, la antropología marxista parte del análisis de prácticas y cosmovisiones de sociedades simples para entender cómo estas 1) son germen de otro tipo de relaciones de producción desiguales, o 2) se yuxtaponen a los modos de producción distintos al comunista, acentuando la dominación y la esclavitud.

El sustancialismo en la antropología ha generado respuestas estáticas a problemas sociales que, en un contexto de dopomodernidad, se nos muestran como dinámicos y procesuales. Hemos visto que la visión costumbrista ha generado una epistemología donde la cultura se torna un objeto de conservación, de análisis comparativo con otros grupos sociales, en la búsqueda de mostrar lo exótico y preservarlo. Por otro lado, la visión holista ha definido la estructura social como un conjunto de relaciones que esclerotizan lo social, detiene su flujo en función de la integración o el inexorable paso a relaciones sociales más equitativas en la economía política. La antropología sustancialista, a propósito o no, sigue proyectando a su objeto de estudio como un artefacto premoderno, en ocasiones inmanente, cuando lo social ya no puede desentenderse de la lógica de la dopomodernidad: la vinculación de los actores sociales mediante relaciones no es tema de la antropología clásica.

\section{LAS IMPLICACIONES TEÓRICO-METODOLÓGICAS DE UNA ANTROPOLOGÍA RELACIONAL}

Un enfoque relacional de la antropología social buscaría, en principio, devolver su carácter social a la antropología misma. El objeto de la disciplina para el presente enfoque es explicar la diversidad en la sociedad dopomoderna, es decir, abordar la proliferación de formas de sentido y de organización social dentro de las relaciones 
sociales, sin caer en las explicaciones de dicha diversidad en función de la proliferación de "culturas", de actores con diferentes procedencias, etnias, preferencias sexuales, como si la definición de los actores fuera constitutivo de lo social. El concepto de "relación social" es central, entendido como "aquella referencia-simbólica e intencional- que conecta sujetos sociales en la medida en que actualiza o genera un vínculo entre ellos, es decir, en cuanto expresa su 'acción recíproca'” (Donati, 2006: 95). Ante problemáticas propias del advenimiento de la dopomodernidad, considero que la antropología clásica, de corte sustancialista, no nos da, por sí misma, respuestas claras a problemáticas como el desplazamiento del espacio físico como base de la organización social, o el análisis de acontecimientos disruptivos (entiéndase performances) más allá de su experimentación directa. Cuando damos el giro relacional a la reflexión antropológica, pasamos del pensamiento entitativo -centralidad de las sustancias- a la distinción reflexiva "por relaciones" -lo que "existe-en-relación" (Donati, 2006: 65-66).

Los antropólogos que abogamos por una perspectiva relacional nos proponemos iniciar un programa de investigación con la meta de obtener una reflexión mucho más humanista desde las ciencias sociales; reflexión que no se ha logrado con las explicaciones sustancialistas del objeto antropológico. También buscamos complejizar la meta de Pierpaolo Donati en el mismo sentido (Donati, 2007: 5), pero evitando el problema de entender lo humano al margen de una explicación sociológica que no problematice la experiencia de la diversidad en sí.

El giro relacional se sustenta, epistemológicamente, en el realismo crítico. Parte de una crítica al empirismo y al neopositivismo lógico que, aun cuando afirman la posibilidad de conocer la realidad, también sostienen que 1) la realidad sólo puede ser confrontada mediante una experiencia controlada por medios científicos, y 2) que el fruto de esta experiencia controlada es la única forma en que la realidad puede ser genuinamente cognoscible: los enunciados científicos (Neurath, 1932-33). De acuerdo con Roy Bhaskar, existe una realidad que puede ser conocida mediante métodos y códigos científicos, pero no solamente puede ser conocida de esa manera. La realidad es cognoscible porque es una relación en sí misma, y se la puede conocer de distintas formas: mediante la experiencia cotidiana, sin una intención manifiesta de crear conocimiento científico; a partir del proceso de socialización, que permite una mirada más sistemática de lo real; y con base en una relación epistemológica, que dará lugar conocimiento científico. A esto se le denomina "estratificación" de la realidad (Bhaskar y Lawson: 1998: 6; Donati, 2007: 2). De acuerdo con Bhaskar (1971), esta perspectiva 
implica un cambio epistemológico y ontológico en la percepción de lo que confrontamos. No se trata ya de experimentar con un “objeto" inmóvil y pasivo.

El marco en el cual se genera el conocimiento puede representarse de la siguiente manera:

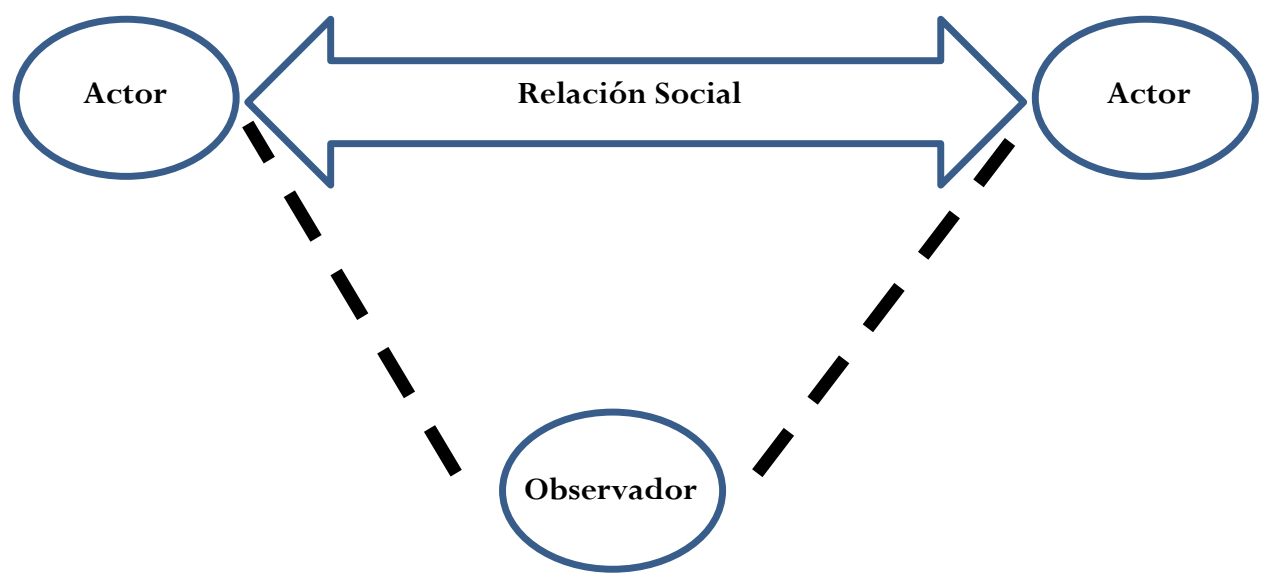

Figura 1. Relación de Conocimiento según el Realismo Crítico

El investigador no se posiciona en la distinción clásica sujeto/objeto, que implicaría una relación de atribución de sentido, en vez de una visión crítica de los fenómenos emergentes de la relación social. Para decirlo en el argot luhmanniano, el investigador, en tanto observador, realiza una "observación de segundo orden", en tanto que es consciente de los elementos que intervienen en la relación y de que, entre tales elementos, los actores, como "observadores de primer orden", no están plenamente conscientes $-\mathrm{y}$ no tendrían necesariamente que estarlo, porque nadie posee una capacidad de observación omnipresente (Luhmann, 2007: 155).

Para el realismo crítico, la relación social implica que el vínculo entre actores no es estático, sino tendiente a una constante transformación, la cual puede darse mediante un fenómeno conocido como "relación"; éste implica que los actores, en su constante interacción pueden propiciar actos que modifiquen la estructura social (Donati, 2006: 93). Dicha tendencia a la modificación puede dar lugar a dos fenómenos importantes para entender el cambio social: la "morfogénesis" o la propensión de los actos relaccionales a cambiar las estructuras y las atribuciones de sentido, y la "morfostasis", propensión contraria en que las estructuras y las atribuciones de sentido se reafirman y mantienen (Archer, 2011: 60). 
El enfoque relacional de las ciencias sociales no desdeña a los actores ni sus atributos como "agentes sociales", aunque no son el centro de la reflexión de esta propuesta. Los actores "hacen algo", pero sólo pueden hacer algo socialmente mediante el vínculo relacional, y es con base en éste que producirán incidencias en la estructura social, utilizando su conocimiento y significación sobre el pasado (iteración), su visión de un futuro posible (proyecto) y partiendo siempre de la acción presente (Emirbayer y Mische, 1998: 963). La visión relacional no privilegia la elección racional ni la visión de individuos maximizadores de beneficios y minimizadores de costos, pues a su interior también se comparten ideas como la de los "efectos no deseados" de la acción agencial (Giddens, 2004) y las implicaciones de lo que Luhmann llama "contingencia”, es decir, la posibilidad de que la comunicación pueda o no transmitir el sentido intencionalmente pensado (Corsi, Esposito y Baraldi, 1996: 68).

Aunque en la disciplina se ha tendido a concentrar las reflexiones antropológicas en el actor o "nativo" (Geertz, 1994; Menéndez, 1997; Long, 2006), el enfoque relacional busca enriquecer los mencionados aportes, añadiendo que los actos simbólicos, la construcción de identidades, la adopción de un punto de vista frente al entorno social y sus constreñimientos, y la generación de acuerdos y disputas sólo pueden ocurrir dentro de la relación y no fuera de ella. Los actores no transforman su entorno aisladamente, menos aún en un contexto de dopomodernidad, donde el espacio se ha relativizado y la construcción de relaciones - de redes sociales- es lo que más ha influido en la capacidad social de vincularse.

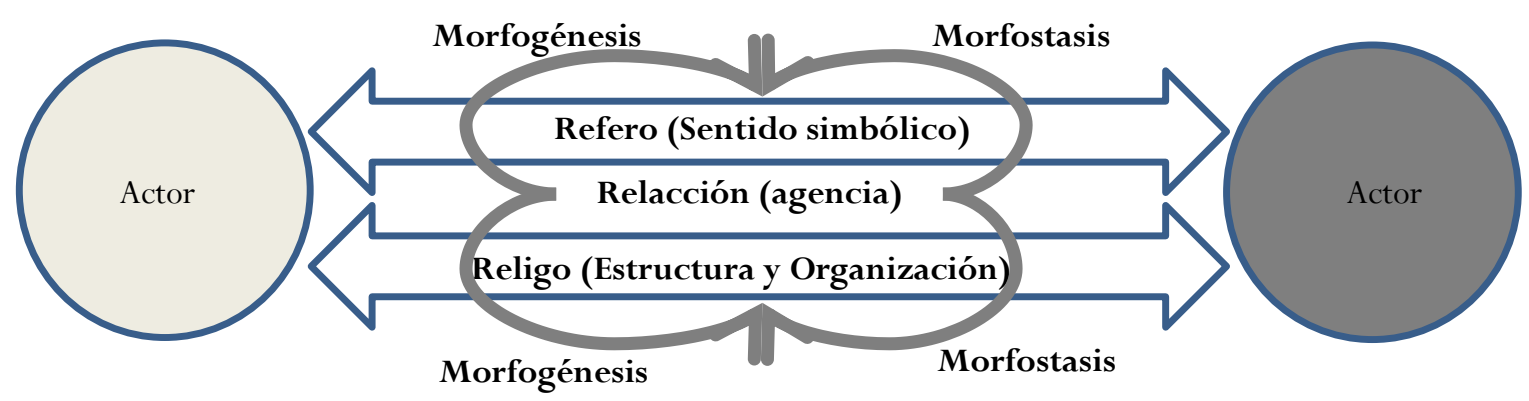

Figura 2. Ontología de la Antropología Relacional

Para profundizar en la lógica del cambio social, Donati distingue entre tres dimensiones de la relación: el "refero", el "religo" y la "relacción". Sobre la última, ya se ha mencionado algunos aspectos, al aludir a la distinción morfogénesis/morfostasis. En 
cuanto a las primeras dos, El "refero" constituye una semántica referencial de sentido simbólico, es decir, "un referir una realidad a otra, dentro de un marco de significados, más o menos compartido por los actores implicados, con diversos tipos y grados de intencionalidad" (Donati, 2006: 93). El "religo" a su vez implica una semántica estructural, es decir, "la sujeción, conexión, atadura, condicionamiento recíproco, estructura, que es al mismo tiempo vínculo y recurso, de carácter personal o impersonal” (Donati, 2006: 93). En el siguiente apartado se abordará con más detalle cada una de estas dimensiones.

Desde una perspectiva relacional, el producto de la investigación será, entonces, la generación de explicaciones sobre el objeto de estudio antropológico; esto no supone, sin embargo, una concepción clásica del concepto -lo que los posmodernos critican como una atribución occidentalizada, proveniente de una investigación que minimiza al nativo (Clifford, 1991: 171). Adoptar el enfoque relacional de una explicación científica implica "dar cuenta de las relaciones que generan un fenómeno como hecho relacional" (Donati, 2006: 62); dicho de otro modo, cuando un investigador analiza un fenómeno que es, forma parte y genera relaciones, debe, primeramente, "comprender" el hecho relacional, es decir, "ponerse en relación” con el fenómeno (Donati, 2006: 62). Afirmamos, desde la relacionalidad, que si bien hay que valorar suficientemente la capacidad heurística del investigador, no es posible dejar de lado la acción, el pensamiento ni el discurso de los actores sociales, que necesariamente entran en juego durante la relación social.

A lo anterior, habrá que agregar una reflexión en torno al problema que Clifford Geertz (1989) y James Clifford (1998) han denominado "la autoridad etnográfica". La etnografía no puede dejar de verse - como muchos otros textos científicos- como lo que es: un relato emitido por un autor. Ante problemas como la centralidad de las relaciones sociales y la consecuente relativización del espacio en la dopomodernidad, es difícil pensar que una etnografía relacional deba evaluar su capacidad heurística en función de su posibilidad de mostrar que el autor “estuvo ahi” (Geertz, 1989: 26). Tampoco puede sostener que dicha heurística dependa del arreglo y la literaturización con la que se cuentan los hechos (Clifford, 1998: 176). Para los antropólogos relacionales, la autoridad etnográfica basada en la capacidad del narrador de mostrar a sus lectores que efectivamente "estuvo" ahí no es más que un fetichismo del registro empírico, en detrimento de la capacidad de análisis del fenómeno observado.

Para el antropólogo relacional, el centro de la descripción etnográfica se basa en la capacidad del etnógrafo de analizar la relación en su mayor complejidad (lo 
simbólico, lo estructural, los actos pragmáticos, etc.). Su intención, entonces, no es fomentar una autoridad etnográfica, sino promover una "autoridad etnológica”, que puede suponer la capacidad del etnógrafo de "observar eso" y explicarlo de manera compleja. La antropología relacional, en su revaloración de la relación social como objeto de estudio, reposiciona al etnógrafo como un observador con mayor agudeza que los actores a los que investiga, pues aunque ellos son los que proveen de discursos y pensamientos, acciones e información sobre formas organizativas, es el etnógrafo quien debe mostrar capacidad crítica sobre toda esa información, así como claridad analítica y pericia en el estudio social.

Este es el punto de partida de una antropología relacional. En las siguientes líneas, intentaré detallar las implicaciones metodológicas que supone la adopción de este paradigma.

\section{LA PROCESUALIZACIÓN DEL CONCEPTO DE CULTURA: REFERO}

La sociedad dopomoderna plantea, como una fase histórica de las relaciones sociales, diversos problemas, especialmente en torno al tema de los símbolos y los significados, y su relación con el concepto de cultura. Para los costumbristas, la cultura se torna construcción humana que debe ser preservada, sujeta a comparación entre grupos sociales y también un fenómeno que puede describirse, pero no explicarse científicamente.. Para los holistas, dichos signos y símbolos forman parte de una estructura de relaciones estáticas, ocasionalmente ahistóricas, pero cuando su historicidad está presente, su significado está construido sobre la base de condiciones estructurales restrictivas para los individuos. A la luz de una sociedad vinculada por relaciones, ambas perspectivas sobre la cultura pueden resultar insatisfactorias.

La más grande dificultad del concepto de cultura utilizado en la reflexión antropológica se halla en lo que históricamente se ha querido expresar con éste. Para Luhmann, dicho concepto ha supuesto una gran limitante para la reflexión social, porque no hay claridad en torno a lo que se desea saber al respecto. Identifica conceptos de cultura que van desde la cultura como ilustración, como cualidad intrínseca de una sociedad o un pueblo, o como alter binario de la naturaleza, entre otras denominaciones, al tiempo que define a las sociedades, pero también a una mentalidad que difiere de su entorno (Luhmann, 1997: 19-20).

En general, hay cultura y culturas, y eso no nos libera de problemas metodológicos varios. La salida luhmanniana es situar a la cultura en el ámbito del 
sentido: "cultura es, dicho en otras palabras, la forma de sentido de la recursividad de la comunicación social” (Luhmann, 1997: 26-27). Esto significa por lo menos dos cuestiones importantes: 1) que la cultura, como sentido, sirve para generar una serie de referencias a objetos, cosas o acciones que no se manifiestan directamente en un momento determinado, y 2) que dicho sentido implica necesariamente, para su funcionamiento al interior de las relaciones sociales, del uso de la memoria, como preservación de información en el tiempo. Vista la cultura de esta manera, podemos referir, específicamente, un problema abordado por la antropología de manera recurrente: la forma en que la producción humana genera significados, y cómo éstos perduran en el tiempo y se ponen en práctica.

Para la propuesta relacional que aquí se sustenta, la dimensión de "refero" es el abordaje de la construcción simbólica de las relaciones, de lo real, de lo que es hecho real en la relación. Esta construcción referencial de significados encuentra su ámbito de codificación en el tiempo, en la memoria, y es por eso que su análisis implica, primordialmente, una reflexión sobre la duración de los significados y los símbolos. Para ello, Donati ha propuesto, por lo menos, tres códigos temporales del sentido: "las relaciones sociales tienen su propio código temporal, al que podemos denominar 'código histórico relacional', distinto del 'código de la interacción' y distinto también del 'código atemporal histórico' (Donati, 2006: 96).

El "código atemporal histórico" existe desde la constitución de lo social. Los actores adoptan, consciente o inconscientemente, este código de significados y símbolos. A partir de él, se asigna sentido al mundo desde que las relaciones sociales existen. Es el origen de los relatos que explican el entorno en el cual las personas nos desenvolvemos y también el origen del lenguaje. Con base en significados y símbolos, los seres humanos pudimos, y aún podemos, otorgarle sentido al mundo. Tal vez el abordaje antropológico más importante de este código sea la obra de Claude LevíStrauss (2014), quien, con su noción de "pensamiento salvaje", explica que la construcción de algunas formas de clasificación está presente a través del tiempo y de los grupos sociales. Tal noción del sentido en la experiencia humana tiene como elemento constitutivo central el signo lingüístico, que representa la relación arbitraria entre un significado (una imagen mental) y un significante (una representación fonética) que no puede ser modificada por la mera voluntad de los actores sociales (Saussure, 1945: 94). Los sistemas de oposición binaria, que son pares de signos opuestos entre sí por lo que refieren, son la base del conocimiento humano y concretamente del lenguaje; por ello, a pesar de ser una presencia constante en las relaciones, el código 
atemporal puede ser analizado desde el enfoque lingüístico-estructural (Lévi-Strauss, 1995: 99).

El "código histórico relacional" pertenece a un momento histórico delimitado. El sentido y los significados comunicados desde este código nacen en el tiempo, pero también pueden morir. Sin embargo, su temporalidad puede definir momentos históricos. Es posible realizar el análisis de los símbolos y discursos históricamente situados tomando como base algunos de los postulados de la "arqueología del saber" de Michel Foucault y de la "descripción densa" de Clifford Geertz, en tanto que 1) el análisis históricamente situado del sentido supone estar atento a los aspectos simbólicos y gnoseológicos que tuvieron validez y legitimidad en una época determinada (Foucault, 1970); y 2) la construcción simbólica históricamente situada no surge sino a partir de la interconexión de significados que pueden generar la constitución de relatos que definan el origen del mundo (cosmovisión) y el tono moral con el cual puede ser definido en las relaciones sociales (ethos) (Geertz, 2004).

Finalmente, el sentido manifiesto a partir del "código de las interacciones" vive y muere con las relaciones cara a cara, las cuales son efímeras y suponen significados que sólo se conservan por breves periodos. En la experiencia de las interacciones es donde el sentido puede llegar no sólo a generar la pauta para la comunicación conversacional cara a cara, sino también un fenómeno sui generis dentro de lo social: la encarnación de las expectativas sociales en la conformación de los estilos de vida y las preferencias en el consumo cotidiano (Bourdieu, 1998), y la corporalización de los símbolos, sea en la forma de vestir o en la naturaleza de las relaciones íntimas entre los actores sociales (Bourdieu, 1986; Foucault, 2002).

Así, el estudio relacional del "refero" busca ir más allá de las limitaciones sustanciales del concepto clásico de cultura, estableciendo como base de la investigación la categoría de "sentido" para un análisis más amplio de la producción simbólica. Por un lado, es posible romper con la idea de una producción simbólica atada a la definición de un grupo social o un pueblo específico, pues su análisis no busca la conservación de la cultura como objeto limitado. Hemos visto, a partir del análisis de los diversos códigos simbólicos, que hay significados que nacen y mueren, y el observador no puede estudiar la producción de símbolos con el objetivo de conservar los significados. Por otro lado, si bien afirmo la existencia de un código simbólico atemporal, su consideración no presupone una inmutabilidad de todas las formas de referenciar el mundo. El código atemporal sólo sirve de base humana para aprehender al mundo y generar comunicación entre los actores sociales. 


\section{LA PROCESUALIZACIÓN DEL CONCEPTO DE ESTRUCTURA: RELIGO}

Para la antropología relacional, la dimensión "religo” supone, principalmente, el análisis de las relaciones sociales como “organización social”. Entenderemos la organización social como una cualidad relacional "que se constituye con base en reglas de reconocimiento que lo vuelven identificable y que le permiten especificar las propias estructuras" (Corsi, Esposito y Baraldi, 1996: 121). La organización es una característica relacional donde se definen posiciones sociales y jerarquías, se atribuyen responsabilidades y se definen dinámicas de integración y conflicto; todo definido a partir de reglas - normas de carácter jurídico institucional o consuetudinario- donde se especifica cuáles serán los incentivos por su cumplimiento o los castigos por su incumplimiento.

La antropología clásica, desde sus enfoque sustancialistas, ha abordado la estructura social como una forma esclerotizada de relaciones sociales, donde si bien las normas determinan jerarquías, posiciones y atribuciones, se ha pensado como una forma de mantener la solidaridad y la cohesión social, así como la reciprocidad y un orden de relaciones de poder que sólo podrá quebrantarse en función del cambio en las condiciones históricas de la producción económico-política. Esto, aunado a la idea persistente de que la estructura social está indefectiblemente vinculada a las características que definen al pueblo o grupo social estudiado, como una forma de preservar las costumbres y el vínculo necesario con el espacio físico donde se desarrolla, ha sido el punto de partida desde el cual se ha seguido abordando el objeto de estudio, como si se tratara de un grupo premoderno, simple, sin conexión con una sociedad global.

La antropología relacional, en tanto perspectiva de análisis pensada para la condición dopomoderna, parte de un enfoque organizacional cuyo modelo de análisis es la "red social". La adopción de este modelo para comprender la lógica organizacional implica no sólo asumir la existencia de vínculos referenciales entre los actores, sino que el vínculo entre los actores genera normas, reglas y roles que lo limitan, aunque también lo proveen de medios de acción (Donati, 2006: 100). En este sentido, lo que puede generar constreñimientos no necesariamente son las normas, sino la forma en que los actores "hagan uso" de la red. Pueden mantenerse posiciones, jerarquías, atribuciones de responsabilidad, pero estas no serán inamovlibles, ni una tendencia indefectible hacia la integración social. Podemos, incluso, "hacer algo" con la red social, 
es decir, lograr cambios en nuestra propia vida a partir de los vínculos entre los actores (vistos como nodos), sin necesidad de generar acciones mediante un espacio físico.

Uno de los principios metodológicos básicos del análisis de redes es el denominado “imperativo anticategórico". De acuerdo con Mustafa Emirbayer y Jeff Goodwin, éste consiste en evitar explicaciones analíticas de procesos sociales, en términos atribuidos a categorías sustanciales, que definen a los actores, sean individuales o colectivos (Emirbayer y Goodwin, 1994: 1414). El análisis de redes sociales debe partir de los vínculos entre actores, pues es ahí donde se realizan como actores mismos.

En el código temporal ahistórico, predomina, como elemento constitutivo, el principio de la "organización dualista". Refiere la distinción, por oposición binaria, que da como resultado niveles jerárquicos, normas, y sanciones (Levi-Strauss, 1974: 166). El desequilibrio entre individuos dentro de una relación social está mediado siempre por un sistema de pares opuestos, desde la división sexual del trabajo hasta la constitución del Estado moderno, pasando por todo tipo de formas organizativas en las relaciones sociales. El seguimiento de este sistema de organización dualista, usualmente, puede derivar en la integración social, aunque en la sociedad dopomoderna esta tendencia puede complejizarse, en tanto que el seguimiento de las normas, jerarquías y la implementación de sanciones también podría suponer el principio de una ruptura organizativa. Podremos ver esto en los códigos temporales siguientes.

Un tipo de organización más complejo puede observarse en el código temporal histórico, en tanto que se constituye jerarquizaciones mucho más elaboradas (presencia y definición de roles), normas con mayor contenido de sanciones en función del momento histórico dado. Sin embargo, esta definición de reglas, roles y sanciones no puede perdurar eternamente, sino que sufre diversos cambios como reacción a las contradicciones propias al interior de las relaciones. Foucault propone un ejemplo de ello en su análisis del paso del "suplicio" al "castigo" como forma de gestionar la sanción al desvío de los sujetos frente a un modelo de acción social legitimado. El suplicio, como forma de sanción propia de la Edad Media, suponía el ajusticiamiento ejemplar, basado en infligir miedo a la sociedad a partir del espectáculo punitivo y del escarnio público; sin embargo, con el advenimiento de la modernidad, el modelo cambió hacia el castigo, que suponía el reencauzamiento del desviante para ser readaptado a la sociedad (Foucault, 2002: 16-17). Lo anterior puede abordarse a partir de un análisis de redes sociales (ARS) que dé cuenta de cómo se subdividen las responsabilidades, los 
puestos jerárquicos, las normas que les dan forma y que regulan la conducta dentro de la organización, cuestión que puede compararse con otras formas organizativas o con las mismas, pero a través de sus variaciones temporales.

Desde la crítica a los enfoques holistas se ha desarrollado un enfoque para problematizar la incidencia del fenómeno organizativo en la vida cotidiana. El germen de dichas propuestas está en Max Gluckman. Crítico de sus antecesores funcionalistas británicos (Radcliffe-Brown, Malinowski, Evans-Pritchard, etc.), Gluckman considera que la reflexión antropológica debe cambiar de rumbo hacia una problemática que exponga, de manera más directa, cómo se afirma el orden social. De acuerdo con Gluckman, estudiar el orden social, conforme a las funciones tendientes a la solidaridad (los intercambios rituales, la magia, la brujería, etc), no debe conducir a verlo como serie de eventos pacíficos que logran estabilizar a la sociedad, puesto que en dichos eventos, aunque como generadores de conflicto social, es donde se ve más claramente la tendencia hacia el orden. Son "situaciones", es decir:

[...] el comportamiento, en cierta ocasión, de miembros de una comunidad como tal, analizado y comparado con su comportamiento en otras ocasiones, de tal forma que el análisis revele el sistema subyacente de relaciones entre la estructura social de la comunidad, las partes de la estructura social, el ambiente físico y la vida fisiológica de sus miembros. (Gluckman, 1958: 7)

La situación, entonces, se muestra como un momento en el cual emergen disputas entre los individuos y pueden darse amenazas, conformación de bandos y acciones contenciosas. A partir del análisis situacional, puede entenderse que el conflicto no es, en sí, una cara distinta a la del orden social, sino que en la contienda se reafirma el carácter orgánico de la sociedad. Los conflictos son parte de la vida social, y las costumbres parecen exacerbar estos conflictos, pero, al hacerlo, estas costumbres también impiden que los conflictos destruyan el orden social en su conjunto. (Gluckman, 2009: 32).

La estructura social, desde la dimensión "religo" no necesariamente implica restricciones a la posibilidad de transformación o una relación directa entre la organización y el espacio físico. Una visión de una estructura organizativa rígida y exclusivamente restrictiva es insostenible, pues la relación social permite entender que los aspectos organizativos de lo social pueden tener más usos que la función integrativa. Las redes sociales, que son el paradigma organizativo de la propuesta relacional, pueden generar cohesión y solidaridad entre los actores (nodos) que la conforman, pero 
también, con base en esa red, los actores están en posibilidad de emprender acciones tales como adquirir derechos translocales o insertarse en el mercado laboral (Granovetter, 1973). Todo esto puede ser el principio de una serie de investigaciones antropológicas, a partir de una forma diferente de pensar el objeto de estudio de la disciplina.

\section{LA TRANSFORMACIÓN SOCIAL COMO DIMENSIÓN DE LAS RELACIONES: RELACCIÓN}

La última dimensión de este análisis se ocupa de la "pragmática de las relaciones sociales". La "relacción" es la dimensión relacional desde la cual es posible generar las acciones a raíz de las cuales se propicia un cambio en las estructuras y los marcos de sentido de las relaciones. En la propuesta de un análisis relacional, Donati (2006) propone el estudio de una gramática "generativa” desde la que los actores, en su vínculo mutuo y sólo desde ahí, pueden producir efectos en lo social, es decir, mostrar "cómo los diversos componentes y sujetos agentes que entran en relación producen un efecto no explicable únicamente desde las propiedades de tales componentes y actores sociales, sino que supone connotaciones cuantitativas y cualitativas propias" (p. 94).

Las implicaciones de esta propuesta podrían tener gran impacto para repensar al objeto de estudio antropológico. Supondría que el estudio de los cambios y continuidades en la vida social no sólo tendrían que mirarse como producto del paso del tiempo o el contacto entre grupos sociales, sino como una acción generada en un marco de relaciones sociales donde 1) el cambio social produce, potencialmente, transformaciones en la estructura organizativa y el sentido (morfogénesis); o 2) donde podrían originarse acciones que actualizan -reproducen, reafirman- el orden social y simbólico (morfostasis). Lo que sugiero, desde el punto de vista relacional, es analizar el cambio social como un "fenómeno pragmático de las relaciones".

Todo tipo de fenómeno pragmático, generativo, necesariamente adquiere sentido a través de la distinción morfogénesis/morfostasis; por ello es el elemento fundamental de la experiencia atemporal en la dimensión relaccional. A partir de dicha distinción, los elementos constitutivos del sentido ("refero") y de las formas organizativas ("religo") adquieren propiedades performáticas. La distinción morfogénesis/morfostasis supone la emergencia de fenómenos que tienden a reproducir o transformar la constitución de las relaciones, lo cual puede atestiguarse a través de tres momentos de análisis: condicionamiento (fase previa al fenómeno morfológico), interacción (momento liminal de la vinculación entre elementos sociales 
productores del evento morfológico) y elaboración (estabilización de la constitución relacional posterior al evento) (Archer, 1995: 168).

La semántica generativa de las relaciones sociales no sería posible sin la presencia del poder, en tanto que la movilización e intercambio de recursos materiales y simbólicos puede propiciar transformaciones en la dinámica misma de las relaciones (Archer, 1995: 296). En este sentido, el cambio social es posible porque los condicionamientos relacionales y los vínculos entre actores lo permiten. Habrá actores individuales o colectivos que puedan resistirse al cambio y movilizar diversos recursos para evitarlo, pero cuando ambos fenómenos sistémicos se presentan es inevitable la consecución de efectos en la relación social. Todo ello lo veremos en el abordaje de los siguientes niveles de experiencia temporal en la dimensión generativa.

Victor Turner explora el carácter morfológico de las acciones simbólicas. Propone que el estudio de los rituales, los conflictos, las disputas, los eventos disruptivos de la cotidianidad, se orienten hacia un enfoque "performático"; en otras palabras, propone una "antropología del performance", un estudio social de los "dramas sociales". Las relaciones sociales no son unidireccionales ni positivas dentro del performance, sino más bien recíprocas y reflexivas; ponen en crisis una narrativa social de la historia y, por ello, pueden transformar lo social (Turner, 1987: 21-22).

La lógica de la interacción entre los participantes divide a los actores performáticos, las audiencias, el escenario (el espacio de las relaciones sociales), el libreto (por lo general, el mito fundante que se reafirma con el ritual o las reglas desde las cuales opera el conflicto) y las relaciones detrás del escenario. La puesta en escena del performance y cómo la audiencia recibe y asimila la forma en que los actores asumen sus papeles, puede determinar si el libreto cambia, si los actores performáticos siguen con sus papeles o los dejan, si el escenario es el adecuado, etc.

Jeffrey Alexander (2006) complejiza dichos argumentos. Advierte de una problemática en el estudio antropológico del performance ritual de Turner; y es que en las sociedades simples, el sentido del performance podía ser compartido por toda una comunidad. Sin embargo, la sociedad actual, con su complejo de redes sociales y perspectivas ideológicas, impide la constitución mecánica de una fusión de sentido entre lo que el actor performático pretende poner sobre la mesa como asunto importante y lo que la audiencia puede considerar importante. Cuanto más sencilla sea la organización colectiva, con mayor consistencia se fusionarán los elementos del performance social; cuanto más compleja sea la colectividad, más de-fusionados se tornarán estos elementos de performance social (p. 32). 
La sociedad dopomoderna tiene mayor relación con lo que Alexander propone como una sociedad segmentaria y diferenciada, en tanto que el sentido y los significados simbólicos no son necesariamente compartidos por todos los actores sociales, y esto es evidente en la esfera de discusión pública, donde los temas vinculantes entre todos los miembros de la sociedad se pueden deliberar y exponer de manera persuasiva para que se tornen de interés colectivo. Ante ello, El objeto del estudio del performance social es analizar cómo las formas simbólicas persuasivas de los actores performáticos generan transformaciones sociales, a través de su relación con las audiencias, con esto se busca rescatar el carácter pragmático de las construcciones simbólicas y culturales, en un esquema relacional operado bajo una lógica teatral dramática (Alexander, 2005: 19).

El carácter pragmático de las relaciones sociales también se manifiesta mediante la generación y uso de las redes sociales. Un ejemplo de este tipo de análisis se halla en los estudios sobre "ciudadanía flexible", de Aiwah Ong (1999). En dicho estudio, la autora analiza cómo mantener el vínculo de una comunidad china, más allá de su propio país, analizando especialmente a un grupo afincado en Estados Unidos. Descubre que su vínculo trasnacional se reafirma cuando los chino-americanos ratifican sus derechos de ciudadanía china, buscando ejercer los derechos y asumir las obligaciones que esto supone fuera de su país; pero si se trata de obtener derechos políticos y sociales en Estados Unidos, la misma comunidad adopta su ciudadanía estadounidense. Los actores chino-americanos, así, no se definen en función de sus atributos personales (como su constitución biológica, sus pensamientos u otros aspectos no sociales), sino en función de su vinculación entre sí y la forma en que relativizan los constreñimientos estructurales. El carácter restrictivo de la red, como estructura de relaciones, se difumina al igual que su anclaje espacial.

En el código temporal de las interacciones, la posibilidad de la transformación social puede darse a través de la representación de dramas sociales en escenarios cotidianos. Es importante diferenciar, pues, la representación de performances sociales a la de dramas sociales, para evitar confusiones en el análisis de la pragmática relacional. Como vimos anteriormente, el performance social surge como una forma en que los actores sociales buscan comunicar el sentido de su condición social a una audiencia considerablemente extendida (la esfera de la opinión pública, por ejemplo), intentando con ello persuadir a tales audiencias de que sus exigencias o posiciones son legítimas.

El drama social, en cambio, se reduce a audiencias más acotadas, generalmente coincidentes en espacio y tiempo, pero también bajo una lógica de transmisión de significados, utilización de objetos cargados de sentido (o su resignificación), formas 
específicas de presentación del self a partir de máscaras sociales y comunicación de emociones y sentimientos (Goffman, 2001: 27). En ese sentido, la implementación de dramas sociales no es ajena a la morfología relacional, en tanto que las máscaras, las formas de expresión de emociones y los mensajes, la búsqueda de la persuasión, el otorgamiento de nuevos significados a objetos y lugares, no pueden ocurrir desde el individuo en su aislamiento, sino a través de la interacción entre actores. Así pues, la lógica del drama social no deja la transaccionalidad de la acción simbólica.

El estudio antropológico de los actos performáticos, de las acciones pragmáticas con capacidades morfogenéticas o morfostáticas puede ampliar nuestra visión de cómo han sido estudiados el ritual, los dramas o los performances sociales. Siendo testigos de una sociedad dopomoderna, es imposible seguir considerando limitada a un espacio físico específico, tanto la existencia de símbolos compartidos por toda una sociedad, como la naturaleza de las situaciones o la acción pragmática de los actos performáticos. La antropología relacional invita a mirar a la sociedad actual de manera diferente, más compleja, con fenómenos que plantean la necesidad de poner en crisis la concepción sustancialista del objeto de estudio antropológico, mirando hacia las relaciones como un reto para comprender nuestro presente.

HACIA UN PROGRAMA DE INVESTIGACIÓN RELACIONAL EN LA ANTROPOLOGÍA: DIFICULTADES Y RETOS

Un proyecto como éste no puede considerarse terminado únicamente desde su enunciación de posibilidad teórica; requiere muchos más esfuerzos. En este sentido, las siguientes líneas detallan aún más el enfoque relacional expuesto, sobre todo para servir como base provisional de futuros estudios empíricos.

La relativa novedad del enfoque relacional en las ciencias sociales obliga a discutir mucho más sus alcances y límites. Si bien los primeros esfuerzos por detallar un enfoque relacional desde las ciencias sociales se remonta a un par de décadas, concretamente desde la sociología, éste es uno de los primeros intentos de pensar la relacionalidad desde la antropología. Esto obliga sin duda a explicar con precisión conceptos tales como "etnografía relacional", "refero", "religo", "relacción"-todos, categorías de análisis antropológico-, así como el giro al análisis del sentido frente al estudio de la cultura, la deslocalización de las relaciones sociales, etc. Hay temáticas clásicas de la antropología social que pueden ser analizadas desde el enfoque relacional: la religión, la política, el género, las identidades y las dinámicas familiares y de 
parentesco que, por cuestiones de espacio, no ha sido posible abordar en este artículo cuyo objeto es fomentar un debate que nos permita revalorar la labor de la antropología en la generación de conocimiento social.

La antropología relacional obliga a los investigadores a abandonar la visión clásica del quehacer investigativo, considerando hasta qué punto la antropología social ha abandonado lo social como su centro de atención. Es muy probable que un giro relacional como el aquí propuesto genere dudas y severas críticas, especialmente porque la teoría y el método clásicos de la antropología se muestran como empresas sustancialistas. Sin embargo, es insostenible que para abordar la diversidad social se utilice enfoques que anteponen la esencia de los individuos a sus formas de crear sociedad. En tiempos de dopomodernidad, la proliferación del sentido y de las formas organizativas en las relaciones debe ser la que defina un nuevo concepto de diversidad.

La dopomodernidad es un hecho, y la antropología relacional se muestra como alternativa eficaz para comprenderla y explicarla. Gracias a los avances tecnológicos, los cambios y transformaciones sociales ocurren actualmente de manera más rápida, sin registrarse de inmediato en nuestro espacio físico. Obtener empleo, hacer efectivos derechos ciudadanos, generar protesta social, posicionar temas de carácter público a nivel global, cimbrar las estructuras, utilizarlas como medio de cambio, mantenernos en constante contacto a pesar de las distancias, conocer de grupos sociales aislados o acceder a videos de las Islas Trobriand, en tiempo real desde la Ciudad de México, son sólo algunos hechos que la dopomodernidad supone, y los antropólogos no podemos mantenernos en la actitud de "llenar odres viejos con vino nuevo". Una nueva configuración de relaciones sociales está presente y la antropología relacional se nos presenta como paradigma con gran potencial heurístico para entender el entorno.

\section{REFERENCIAS}

Alexander, J. C. (2006). Cultural Pragmatics: social performance between ritual and strategy. En Alexander, J. C., Giesen, B. y Mast, J. L. (Eds.), Social performance.Symbolic action, cultural pragmatics and ritual. London: Cambridge University Press.

- (2005). Pragmática Cultural: un nuevo modelo de performance social. Revista Colombiana de Sociología (24). 
ARCHER, M. (2011). Morphogenesis: Realism explanatory framework. En MACCARINI, A., Morandi, E., y Prandini, R. (Eds.), Sociological Realism. London: Routledge. . (1995). Realist Social Teory: The Morphogenetic Approach. The Cambridge University Press.

Benedict, R. (1934). Patterns of culture. Boston: Houghton Mifflin Company. . (2006). El crisantemo y la espada. Madrid: Alianza Editorial.

BHASKAR, R. (1971). The possibility of naturalism. A philosophical critique of the contemporary human sciences. London: Routledge.

, y LAWSON, T. (1998). Introduction: basic texts and developments. En ARCHER, M., Bhaskar, R., Collier, A., Lawson, T., y Norrie, A. (Ed.), Critical Realism. Esencial Readings. London: Routledge.

BoAs, F. (1964). Cuestiones fundamentales de antropología. Buenos Aires: Ediciones Solar. Bourdieu, P. (1998). La distinción. Criterios y bases sociales del gusto. Madrid: Taurus. . (1986). Notas provisionales sobre la percepción social del cuerpo. En Materiales de Sociología Crítica. Madrid: La Piqueta.

Clifford, J. (1991). Sobre la alegoría etnográfica. En ClifFord, J. Y MARcus, G. (Eds.), Retóricas de la Antropología. Madrid: Júcar.

Corsi, G., EsPosito, E. y BARALDI, C. (1996). GLU. Glosario sobre la teoría social de Niklas Luhmann. México: Anthropos-ITESO-UIA.

Descola, P. (2004). Las cosmologías indígenas de la Amazonía. En Surrallés, A., y García Hierro, P. (Eds.), Tierra adentro. Territorio indígena y percepción del entorno. Copenhague: IWGIA.

Donati, P. (2011). Relational Sociology. A new paradigm for the social sciences. Londres: Routledge.

. (2007). Birth and development of the Relational Theory of Society. Relational Studies. Recuperado de https: / / goo.gl/ J2kbD1

. (2006). Repensar lo social. El enfoque relacional. Madrid: Ediciones Internacionales Universitarias.

Emirbayer, M. (2009, julio-diciembre). Manifiesto en pro de una sociología relacional. Revista CS en Ciencias Sociales (4).

, y Mische, A. (1998). What is agency? The American Journal of Sociology, 103(4).

, y Goodwin, J. (1994). Network analysis, culture and the problem of agency. The American journal of Sociology, 99(6).

EVAns-Pritchard, E. (1974). Ensayos de antropología social. México: Siglo XXI.

Foucault, M. (2002). Vigilar y Castigar. Nacimiento de la Prisión. México: Siglo XXI. 
. (1998). Historia de la locura en la época clásica. Cali: FCE Colombia.

. (1970). Arqueología del saber. México: Siglo XXI.

GeErTz, C. (1994). Conocimiento local. Madrid: Paidós.

. (1989). El antropólogo como autor. Madrid: Paidós.

GidDens, A. (2004). La constitución de la sociedad. Buenos Aires: Amorrortu.

Gluckman, M. (2009). Costumbre y conflicto en África. Lima, Perú: Fondo Editorial $\mathrm{UCH}$.

- (1958). Análisis de una situación social en Zululandia Moderna. Rhodes Livingstone Paper (28). Traducción: Clásicos y Contemporáneos en la Antropología. CIESAS-UIA-UAM. Manchester.

Goffman, E. (2001). La presentación de la persona en la vida cotidiana. Buenos Aires: Amorrortu.

Granovetter, M. (1973). La fuerza de los vínculos débiles. American Journal of Sociology, 8(76). Traducción de María Ángeles García Verdasco.

Kroeber, A. (1939). Cultural and natural areas of native North America. Stanford: University of California.

LÉVI-STRAuSS, C. (2014). El pensamiento salvaje. México: FCE. . (1995). Antropología Estructural. Mito, Sociedad, humanidades. México: Siglo XXI. . (1981). Las estructuras elementales del parentesco. Madrid: Paidós. . (1974). Antropología estructural. Madrid: Paidós.

Long, N. (2006). Sociología del Desarrollo. Un enfoque centrado en el actor. México: CIESAS-El Colegio de San Luis.

Luhmann, N. (1997). La cultura como concepto histórico. Historia y Grafía (8).

LyOTARD, J.-F. (1987). La condición posmoderna. Madrid: Cátedra.

MalinOWSKI, B. (1986). Los argonautas del pacífico occidental. Barcelona: Planeta de Agostini.

. (1984). Una teoría científica de la cultura. Madrid: Sarpe.

Mauss, M. (1971). Sociología y antropología. Madrid: Tecnos.

Mead, M. (1993). Adolescencia, sexo y cultura en Samoa. Buenos Aires: Paidós.

MENÉndEZ, E. (1997). El punto de vista del actor. Relaciones (XVIII), Invierno.

MeILlassouX, C. (1989). Mujeres, graneros y capitales. Economía doméstica y capitalismo.

México: Siglo XXI.

Neurath, O. (1981). Proposiciones protocolares [1932-33]. En Ayer, A. J. (Comp.), El positivismo lógico. México: FCE. 
Ong, A. (1999). Flexible citizenship. The cultural logics of Transnationality. Durham: Duke University Press.

RAdClifFe-Brown, A. R. (1974). Estructura y función en la sociedad primitiva. Barcelona: Ediciones Península.

Rosaldo, R. (2000). Cultura y verdad. Quito, Ecuador: Ediciones ABYA-YALA.

Saussure, F. (1945). Curso de Lingüística General. Buenos Aires: Editorial Losada.

TuRner, V. (1987). The anthropology of performance. New York: PAJ Publications.

TYLER, S. (1991). Etnografía posmoderna: desde el documento de lo oculto al oculto documento. En Clifford, J. y Marcus, G. (Eds.), Retóricas de la antropología. Madrid: Júcar.

Viveiros de Castro, E. (2004). Perspectivismo y multinaturalismo en la América Indígena. En Surrallés, A. y García Hierro, P. (Eds.), Tierra adentro. Territorio indigena y percepción del entorno. Copenhague: IWGIA. 